\title{
Demonstration of a Technology Neutral Control Architecture for Providing Frequency Control Using Unidirectional Charging of Electric Vehicles
}

\author{
Askjær, René Juul; Andersen, Peter Bach; Thingvad, Andreas; Marinelli, Mattia
}

Published in:

Proceedings of the $55<$ sup $>$ th $</$ sup $>$ International Universities Power Engineering Conference 2020

Publication date:

2020

Document Version

Peer reviewed version

Link back to DTU Orbit

Citation (APA):

Askjær, R. J., Andersen, P. B., Thingvad, A., \& Marinelli, M. (2020). Demonstration of a Technology Neutral

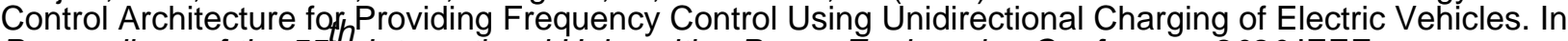
Proceedings of the 55 International Universities Power Engineering Conference 2020 IEEE.

\section{General rights}

Copyright and moral rights for the publications made accessible in the public portal are retained by the authors and/or other copyright owners and it is a condition of accessing publications that users recognise and abide by the legal requirements associated with these rights.

- Users may download and print one copy of any publication from the public portal for the purpose of private study or research.

- You may not further distribute the material or use it for any profit-making activity or commercial gain

- You may freely distribute the URL identifying the publication in the public portal 


\title{
Demonstration of a Technology Neutral Control Architecture for Providing Frequency Control Using Unidirectional Charging of Electric Vehicles
}

\author{
René Juul Askjær, Peter Bach Andersen, Andreas Thingvad, Mattia Marinelli \\ Department of Electrical Engineering, Technical University of Denmark (DTU) \\ Ris $\varnothing$ campus, Roskilde, Denmark \\ \{renas, pba, athing, matm\}@elektro.dtu.dk
}

\begin{abstract}
This paper demonstrates a control strategy for providing primary frequency regulation from electric vehicles using unidirectional charging. The control architecture developed is tested and deployed in multiple locations using both commercial and test chargers relying on IEC 61851 communication with commercially available electric vehicles. The tests are conducted in a university campus area using commercial chargers and at a test-site at the Danish island of Bornholm. The results from Lyngby shows that the control architecture is able to control the charging of multiple unknown electric vehicles simultaneously in order to provide aggregated primary frequency regulation according to the tender requirements of the Danish Transmission System Operator, Energinet, for the Nordic region DK-2. The results from Bornholm shows a faster response of the control architecture, as the communication flow is optimized and the overall response time is lowered.
\end{abstract}

Index Terms-Ancillary Services, Electric Vehicles, Frequency Control, Unidirectional Charging

\section{INTRODUCTION}

Many European countries will, in the next 10-15 years, experience a massive amount of new electrical vehicles (EVs) in the streets of Europe. Many European countries have, as a response to the current climate challenges, passed or proposed regulation that effectively ban the sale of personal vehicles with internal combustion engines [1]. The International Energy Agency projects that electric Light-Duty Vehicles (LDV) will have a market share of close to $40 \%$ in Europe in 2030, this includes both battery-electric and plugin-hybrid [2]. In the mean time, transmission system operators (TSOs) are preparing for a future with increased amount of distributed generation based on renewable sources, this can jeopardize the stability and reliability of the power system due to the intermittent nature of the production output [3]. Using EV battery systems as an active part of the power grid could therefore become an essential part of the plan to support the power grid. EVs ability to change their charging current within seconds make them a good candidate for providing primary frequency regulation (PFR). Using a realistic implementation, the authors of [4] have attempted to minimize the fleet cost of operation by participating in the California Independent

Part of the work in this paper has been supported by the research project ACES (EUDP grant nr: EUDP17-I-12499). www.aces-bornholm.eu
System Operator (CAISO) frequency regulation market. The University of Delaware has been using university owned EVs to participate in the regulation marked of Pennsylvania, New Jersey and Maryland (PJM) which is the largest TSO in the world. A comparison of a centralized vs decentralized method was simulated, as issues arises as the computation time needed to calculate bid capacity is growing exponentially with the numbers of participating EVs [5]. In [6], the authors deploy a multi-agent system to participate in the PJM market. In [7] the economic factors of Vehicle-to-Grid (V2G) and charger efficiency is evaluated, where [8] reports on the first commercial V2G hub in the Nordic Area.

This paper looks at an important challenge of integrating EVs as future part of the power grid. The specific PFR in the Nordic power system, Frequency-controlled Normal operation Reserve (FCR-N) as defined by ENTSO-E, can be delivered by EVs which can prove to be vital in the future operation of the power system. The paper focuses on unidirectional charging as this give lower wear of battery, requires less hardware and is simpler to implement in larger scale. In the makings of this paper, the authors has conducted multiple tests at two locations, at university campus in Lyngby and the Danish island Bornholm. This paper present results from those tests that include positive findings and challenges to be addressed in future research.

The remainder of the paper is structured as follows. Section II presents the requirements for providing FCR-N in the DK-2 area where the tests have been conducted. The section follows with a generic description of the methodology used for the test setup at both University Campus Lyngby and a test setup of Bornholm as well as a description of the communication architecture used to enable the tests. In Section III a more detailed description of the setup and control architecture at Lyngby Campus is presented along with the results of the test. Section IV continues on the learning's from the previous section and describes the setup and control architecture used at the test on Bornholm along with the result of the test. Section $\mathrm{V}$ presents a more analytical approach to compare the results of both tests. Section VI concludes the paper and gives a short discussion of some of the future works to be done. 


\section{Methodology}

The test setup follows the tender conditions of the Danish Transmission System Operator (TSO) Energinet [9] for region DK-2, with respect to how the ancillary service should be delivered. The main aspects of the tender condition that the tests will follow is that in the DK-2 region the service has to be supplied at a frequency deviation of $\pm 100 \mathrm{mHz}$ relative to the reference frequency of $50 \mathrm{~Hz}$. The service has to be delivered linearly between $49.9 \mathrm{~Hz}$ and $50.1 \mathrm{~Hz}$ without any deadband. The main aspect of this ancillary services is to keep the equilibrium between production and consumption, and it is supposed to be delivered automatically when frequency deviations occur. Normally a market participant would be required to provide a minimum of $0.3 \mathrm{MW}$ of regulation power in order to participate in the service. As these tests are done for demonstration purposes, the $0.3 \mathrm{MW}$ regulation power requirement is neglected.

\section{A. IEC 61851 Standard}

The standard for Electric Vehicle Supply Equipment (EVSE) $\rightarrow$ EV communication used at both locations is IEC 61851 [10]. This standard describes a PWM control signal in the charging cable that sets a limit of the maximum current the connected EV is allowed to charge with. The minimum charging current on each phase is $6 \mathrm{~A}$ and the maximum is $80 \mathrm{~A}$, though often limited by the installed equipment to respectively 16,32 or $63 \mathrm{~A}$. As most EVs will charge with the maximum allowed power, if the internal charger is capable, the PWM signal essentially becomes a control signal for controlling the charging of each EV. Only in the last part of the charging cycle, when the state-of-charge (SOC) reaches around $80 \%$ and above that the EV might draw less power than allowed, as the charging cycle switches from constant current charging to constant voltage charging. This is one of the main drawback of using this standard for FCR-N, as the signal sent from the EVSE to the EV is merely a control signal. The signal is seen by the EV as the threshold of charging and one cannot be sure that the connected EV will follow the signal precisely. Another drawback of the standard is that the communication is one-way only. This results in missing information of battery SOC, which makes it very difficult to do capacity calculations when moving towards a large-scale setup. IEC 61851 allows for changes of 0.7A, but real world implementation often only allows for 1A discrete changes, while the requirement of Energinet specify that the regulation has to be provided linearly. In order to reach the specified minimum regulation power, an aggregator would be required to have a sufficient pool of vehicles, which would make it possible to send differentiated control signals to the individual EVs to achieve a more linear response.

\section{B. Control Architecture}

The basic test setup consists of an aggregator/controller which receives local power and frequency measurements from a locally installed measurement device. The aggregator calculates a charge set point based on the obtained measurements

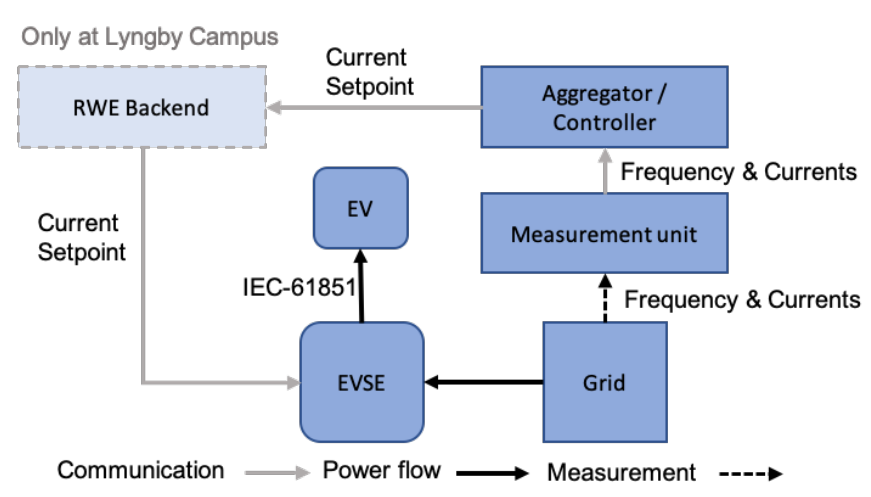

Fig. 1. Illustration of the communication flow used for both test setups

and transmits these to each EVSE. Each EVSE communicates with an EV through IEC 61851. The communication and control setup is depicted in Fig. 1. The communication and control strategies are used independently at two different locations; a public office parking area at Lyngby Campus north of Copenhagen and a test location at the Danish island of Bornholm south of Sweden. The communication between the controller and the EVSE at Lyngby Campus goes through a third-party server, namely the RWE-backend, as there is no direct control possibilities available in the EVSE. This is further elaborated in section III. The controller at Bornholm is communicating directly with the EVSE.

Measurement unit: The frequency measurement device used for the test is a DEIF mtr-3 meter from which the controller pulls measurements. The DEIF meter supports frequency measurements with a precision of $\pm 10 \mathrm{mHz}$ with a time-resolution of $200 \mathrm{~ms}$.

Aggregator/Controller: The core of the setup is the controller which handles all communication and calculations. The control characteristics are achieved through the use of a droop controller, as the desired charging set point will change as a function of the measured frequency. As a concept, the Preferred Operating Point (POP) is introduced [5] for bidirectional chargers operation as a way to compensate for the round-trip loss when providing V2G and to reach a desired SOC at the end of a charging session. This specific setup follows the same approach described in [11] to provide a symmetric frequency reserve with only unidirectional charging, but differs as this research has been outside a lob environment. For EVs with unidirectional charging the POP is the desired charging current if the frequency is stable at the reference point of $50 \mathrm{~Hz}$. From this point the charging current is altered with the use of a droop constant, in order to provide frequency regulation. By altering the POP to a higher value results in a lower regulation capacity, but provides a higher level of charging. A calculation of the POP is reported in (1), and shows how to provide the highest amount of regulation capacity available. The POP is calculated specific for each location, as the maximum current available at EVSE level at the test locations differs. 


$$
\begin{gathered}
P O P=I_{\text {max }}-\frac{I_{\max }-I_{\text {min }}}{2} \\
d \text { roop }=\frac{f_{\text {max }}-f_{\text {min }}}{I_{\text {max }}-I_{\text {min }}} \\
I_{\text {charge }}=\frac{f_{\text {mes }}-f_{\text {ref }}}{d \text { roop }}+P O P
\end{gathered}
$$

The droop constant is calculated in (2) using site specific values reported in table I and II [12]. In (3) the actual charge set point is calculated using the measured frequency and the values calculated in (1)-(2). This calculation runs each time a new frequency measurement has been obtained.

RWE-backend: The EVSE installed at Lyngby campus is from the German energy company RWE. Communication with the EVSE is enabled by a RWE controlled API. This part of the communication flow is considered a "black-box", as the controller sends a charge set point and the EVSE responds by changing the charge set point. The RWE-backend is only present in the setup at Lyngby Campus.

EVSE: All EVSE that support IEC 61851 and allow for external communication can be used.

\section{DESCRIPTION AND RESUltS: LYNGBY CAMPUS}

This section describes the setup at Lyngby Campus, the applied control characteristics and presents the results of of the test.

\section{A. Description of Setup}

In order to use EVs for FCR-N it must be possible to control the charging of each vehicle. The EVSE used for the experiment is series-produced EVSE from the German energy company RWE. Each EVSE is connected over the internet to a RWE backend system that enables bi-directional communication with the EVSE through an API. Each EVSE has 2 outlets that supports $11 \mathrm{~kW}, 16 \mathrm{~A}$ of 3-phase $\mathrm{AC}$ charging complying with IEC 61851 . The test setup includes 3 EVSE, resulting in a maximum consumption of $66 \mathrm{~kW}$ equivalent to $96 \mathrm{~A}$ on each phase.

Using commercially available EVSE introduced numerous challenges, assumably because the RWE backend system was not designed to handle frequent changes in the requested charge in such a short period of time. In many of the early attempts to control the charging, the system became totally non-responsive. To address this challenge, a choice was made to only control the charging from a single EVSE [13].

B. Site Specific Control Description

TABLE I

VALUES USED IN (1) - (3) TO PRODUCE (4)

\begin{tabular}{ll}
\hline$f_{\max }$ & $50.1 \mathrm{~Hz}$ \\
\hline$f_{\min }$ & $49.9 \mathrm{~Hz}$ \\
\hline$I_{\max }$ & $16 \mathrm{~A}$ \\
\hline$I_{\min }$ & $6 \mathrm{~A}$ \\
\hline Regulation capacity & $\pm 3.4 \mathrm{~kW}$ \\
\hline
\end{tabular}

Table I shows the values used in (1) - (3) to to create the charge controller specific for this test setup in (4). The $I_{\max }$ of $16 \mathrm{~A}$ is the upper charging limit at this location.

$$
I_{\text {charge }}= \begin{cases}6, & \text { if } f_{t}<49.9 \mathrm{~Hz} \\ \frac{\Delta f}{0.02}+11, & \text { if } 49.9 \mathrm{~Hz} \leq f_{t} \leq 50.1 \mathrm{~Hz} \\ 16, & \text { if } f_{t}>50.1 \mathrm{~Hz}\end{cases}
$$

\section{Result from Lyngby}

A 30 min sample of the measured data from the test is reported in Fig. 2. The measured data consists of $2 \mathrm{EVs}$ charging simultaneously at one EVSE, the resulting response of the controller is therefore $2 \cdot I_{\text {charge }}$.

When inspecting the plot, it seems that the measured charging current (blue line) is following the oscillations of the frequency very well. It is however difficult to visually observe the precision of the controller. As seen in Fig. 2 the current is a slightly below the set point by approx. $1 \mathrm{~A}$. This phenomena is caused be the internal charger undershooting [14]. The response time of the controller regarding the changes in the frequency seems to be constant. It follows the frequency oscillations very well, it is however difficult to see whether or not it is lagging. The fast response of the setup can be appreciated at the two spike at 07:42 and 07:46, where the controller manages to follow the short frequency deviation very well.

In Fig. 3 a 200 s. excerpt of the plot in Fig. 2 is shown to better appreciate the details of the frequency oscillations and the resulting charge from the connected EVs. The plot shows that the change in the charge current lags the frequency change, as would be expected. The communication loop is quite long as the controller doesn't directly control the EVs through the EVSE, but the communication goes through a third-party server that then handles communication with the EVSE. Adding more steps to the communication cycle will naturally increase the response time of the total system. It can also be observed that the system response follows downregulations faster than up-regulations. It is visible at the last frequency oscillation from 07:49:30 until end of plot. The time-lag of the blue curve seems greater when $\frac{d f}{d t}$ is positive, compared to the opposite when $\frac{d f}{d t}$ is negative. Looking through the timestamped data reveals that the up-regulation

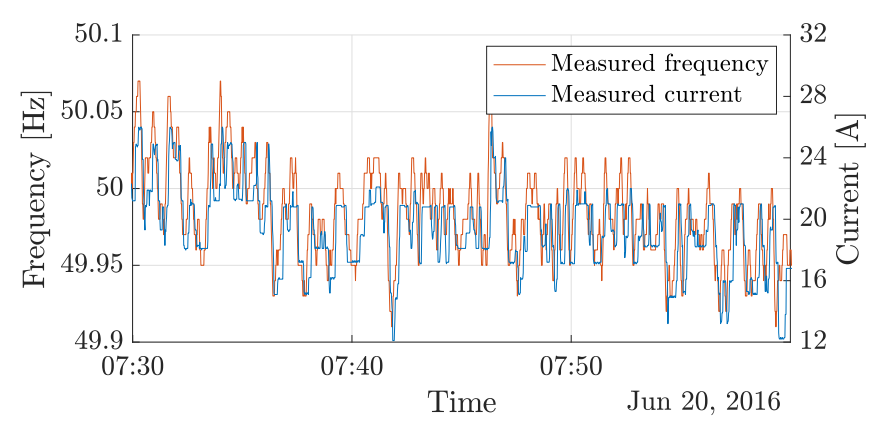

Fig. 2. Measured frequency and Phase A EV current at Lyngby Campus 


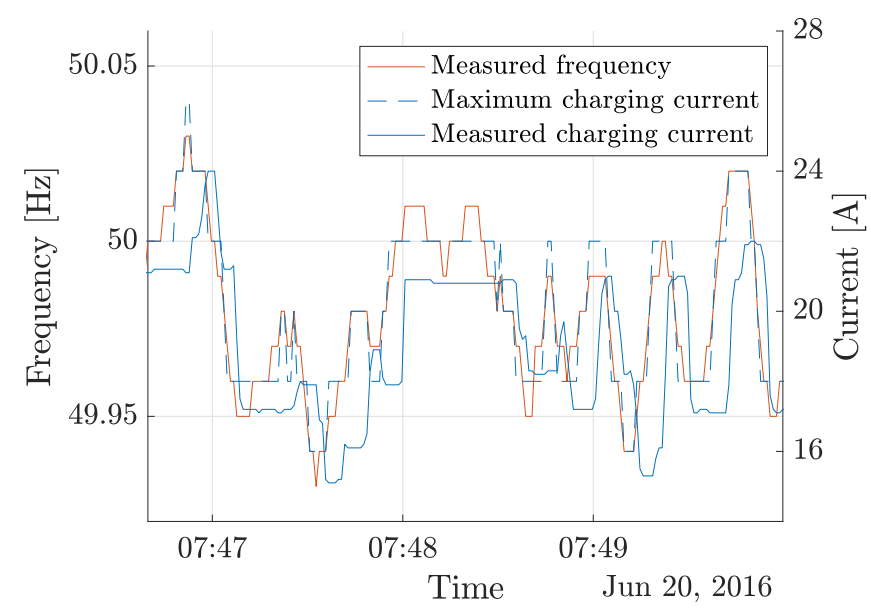

Fig. 3. Excerpt of the measured frequency and Phase A EV current at Lyngby campus

was in progress after $6 \mathrm{~s}$. but the response was not complete until after $7 \mathrm{~s}$. The down-regulation was completed after 3 s. By times-shifting the measured the frequency, the highest correlation was found to be at $5 \mathrm{~s}$., meaning that the average response of the system is delayed by $5 \mathrm{~s}$.

In order to better evaluation the response, a correlation between phase A EV current and frequency measurements is reported. The plot of Fig. 4 reports this correlation, highlighting also the applied control characteristic (red solid curve). Notice the control characteristics of the total system response is $2 \cdot I_{\text {charge }}$ from 4 as seen in the left side of the figure, the right side contains the $2 \mathrm{EVs}$ individual correlation. In a perfect system without time-delay the dots would follow the red solid curve, but the figure resembles more a cloud of dots. A slight overweight of dots on the right side of the control characteristics in the left subplot can be noticed. This observation can also be seen at the correlation of the lower right subplot, though with even more overweight on the right side. The right-sided overweight is a result of the EV

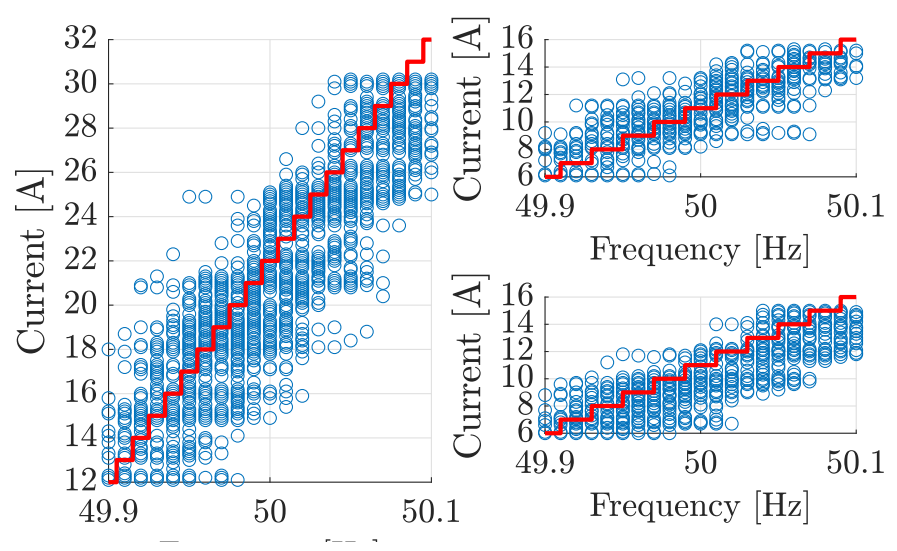

Fig. 4. Correlation of phase A EV current and frequency measurements at Lyngby Campus. The left side correlation plot depicts the correlation of 2 EVs charging, and the right side show the correlation of each EV. consistently charging below the desired set point. The dots in the upper right subplot seems more evenly distributed around the red solid line. It can also be observed the that total response never exceeded 30A, even though the frequency at multiple occasions was at a level that should have resulted in a response of 32A. A more analytical approach to the correlation of the current and frequency can be found in section $\mathrm{V}$.

\section{DESCRIPTION AND RESUltS: BORNHOLM}

This section describes the setup at Bornholm, the applied control characteristics and presents the results of of the test.

\section{A. Description of Setup}

In order to minimize the response time of the total system, the test setup at Bornholm is using an EVSE with the controller software built-in. By removing the RWE-part of the communication loop, an improved response time should be noticeable in the results.

\section{B. Site Specific Control Description}

The EVSE used for the tests at Bornholm is capable of delivering 32 A per phase, resulting in an upper limit of $22 \mathrm{~kW}$. The POP is therefore increased to $19 \mathrm{~A}$ as a result of the maximum charging current is raised to $32 \mathrm{~A}$ as reported in 5 .

TABLE II

VALUES USED IN (1) - (3) TO PRODUCE (5)

\begin{tabular}{ll}
\hline$f_{\max }$ & $50.1 \mathrm{~Hz}$ \\
\hline$f_{\min }$ & $49.9 \mathrm{~Hz}$ \\
\hline$I_{\max }$ & $32 \mathrm{~A}$ \\
\hline$I_{\min }$ & $6 \mathrm{~A}$ \\
\hline Regulation capacity & $\pm 9.0 \mathrm{~kW}$ \\
\hline
\end{tabular}

Be applying the values of II to equations 1-3 the resulting response of the system can be seen in 5

$$
I_{\text {charge }}= \begin{cases}6, & \text { if } f_{t}<49.9 \mathrm{~Hz} \\ \frac{\Delta f}{0.0077}+19, & \text { if } 49.9 \mathrm{~Hz} \leq f_{t} \leq 50.1 \mathrm{~Hz} \\ 32, & \text { if } f_{t}>50.1 \mathrm{~Hz}\end{cases}
$$

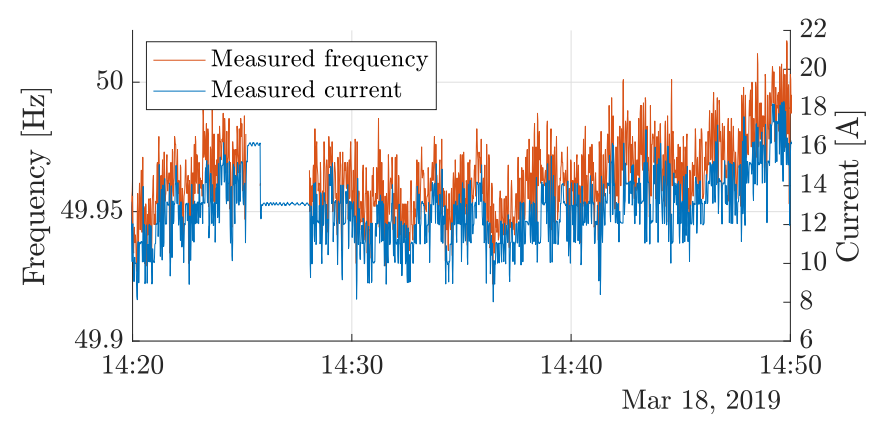

Fig. 5. Phase A EV current and frequency measurements at Bornholm 


\section{Result from Bornholm}

The measured data from the test is reported in Fig. 5. The reported plot reveals an interesting thing; at around 14:25 the frequency measurements halts leaving the EV at a constant charge of 13A until 14:28 where the controller resumes normal operation. The figure also reveals that the charge current is below the set point of around 1A. As with the test at Lyngby campus, the EVs ability to charge at the maximum allows set point is not related to the controller, but it is the internal charger in the EV that is charging below the limit. The reported time frame of the plot was intentionally chosen to highlight one of the challenges of building reliable system. The issue with the missing frequency measurements brings to attention the quality of frequency measurements needed to continuously provide PFR. It is important to develop the system in such a way that it is resistant to failure of one device or measurement equipment. It is however not economically feasible to install frequency measuring equipment in each EVSE, and therefore a compromise has to be made. This compromise could be to implement a N-1 scenario such that each vital device has a backup device. It would be possible for the controller to receive 2 different frequency measurements, possibly not electrically too far from each other. By using simple logic, faulty measurements could be discarded and the service would continue to run uninterrupted.

Reported in Fig. 6 is a $3 \mathrm{~min}$. excerpt of the charging session, to better appreciate the details of the frequency oscillations. This specific excerpt was chosen because The island of Bornholm, normally electrically interconnected with Sweden, was electrically islanded at 15:28, marked with a grey vertical line. At this point in time the power system at Bornholm was cutoff from the rest of the Nordic power system. The short term fluctuations of the whole Nordic power system disappears as the time between the fluctuations increases as does the magnitude of the fluctuation. The decrease in frequency fluctuations reveals that the inertia of the system has been decreased noticeably and the inter-area oscillations disappears. The disappearing of the fluctuations reveals the charging current (blue line) follows the frequency very close time-wise. It is also more observable that the connected EV is below the desired charging set point consistently with around 1A. The desired charging set point is also visualized in the

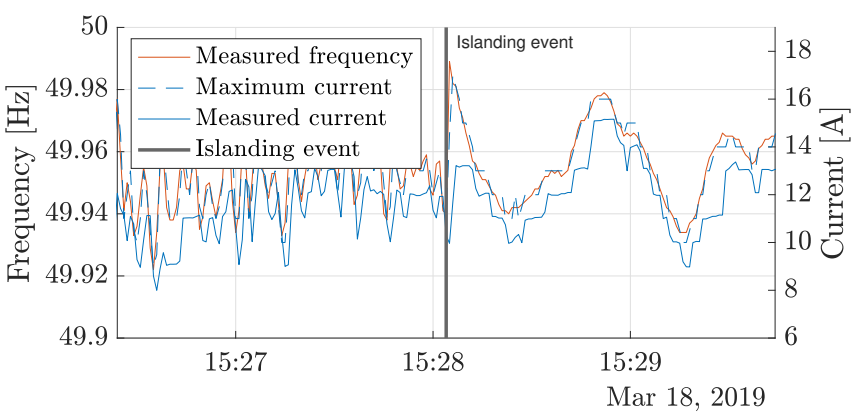

Fig. 6. Excerpt of the measured current and frequency at Bornholm

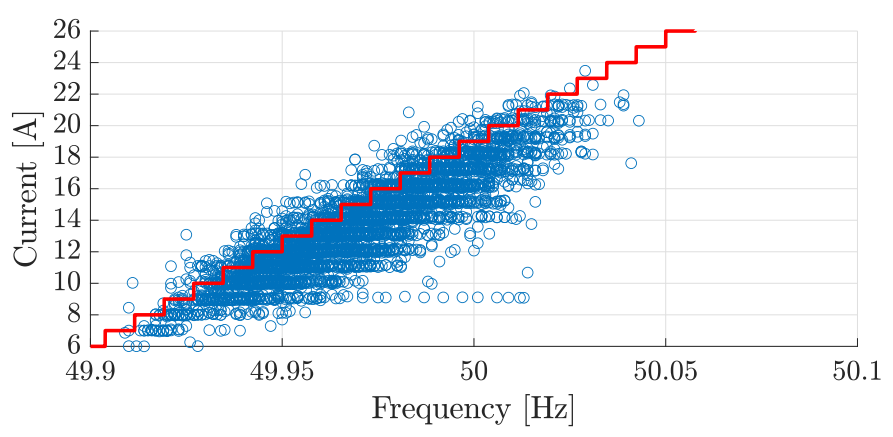

Fig. 7. Correlation between charging current and frequency at Bornholm

figure with a blue dotted line, this is the charge set point sent to the EV. As with the results reported in 3 it seems that downregulation happens faster than up-regulation. By removing the RWE-part of the communication loop and controlling the EV charging set point directly at the EVSE, the average time lag of the system has been decreased to $1.5 \mathrm{~s}$, though the difference between up- and down-regulation is still present.

As with the results of the test at Lyngby Campus, in order to get a more clear evaluation of the response time of the system, a correlation between phase A EV current and frequency measurements is reported. The plot of Fig. 7 reports this correlation, highlighting also the applied control characteristic (red solid curve). The correlation is based on 5000 measurements. The first impression is that the cloud seems reasonable more dense and it follows the control characteristics very well. The undershooting phenomena can again be observed as the cloud is right-shifted.

\section{COMPARING THE RESUlTS}

In order to get a better evaluation of the response time and to analytically support the assumption of the lower response time at Bornholm, a numerical correlation analysis is reported in table III. The correlation analysis is done by considering time shifts between 3 and 7 s. for Lyngby Campus and between 0 and $4 \mathrm{~s}$. for Bornholm [11]. Three classes are evaluated and the evaluation is based on a 20 min time series.

I calculated-I set: Correlation between the calculated current set point, calculated from the measured frequency and the current set by the controller. It can be seen that at both locations the highest correlation is obtained without time shift, as the highest correlation at Lyngby Campus is $98.66 \%$ and $97.34 \%$ for Bornholm. It is therefore reasonable to assume that the controller delay is between 0 and $0.5 \mathrm{~s}$.

I set-I measured: Correlation between the current set by the controller and the measured current consumed by the EVs. The highest correlation is found for Lyngby Campus in column 3 (5 s. shift) although the surrounding columns have high correlations. For Bornholm the highest correlation is found in the second column $(2 \mathrm{~s}$. shift). The difference in response time indicate that the removal of the RWE-backend from the communication flow resulted in a decrease in response time of $3 \mathrm{~s}$. at Bornholm. It is important to point out that this correlation also considers the mismatch of the measured and 
TABLE III

CORRELATION BETWEEN CALCULATED/SET/MEASURED PHASE CURRENTS - DATA SET $1800 \mathrm{~s}$.

\begin{tabular}{|c|c|c|c|c|c|}
\hline Lyngby Campus & 0s shift & 1s shift & 2s shift & 3s shift & 4s shift \\
\hline \multirow[t]{2}{*}{ I calculated - I set } & $98.66 \%$ & $97.77 \%$ & $96.44 \%$ & $94.59 \%$ & $92.34 \%$ \\
\hline & 3s shift & 4s shift & 5s shift & 6s shift & 7s shift \\
\hline \multirow[t]{3}{*}{ I set - I measured (ph A; ph B; ph C) } & $95.90 \%$ & $97.17 \%$ & $97.77 \%$ & $97.60 \%$ & $96.77 \%$ \\
\hline & $95.55 \%$ & $97.01 \%$ & $97.42 \%$ & $96.77 \%$ & $95.27 \%$ \\
\hline & $95.52 \%$ & $96.97 \%$ & $97.39 \%$ & $96.78 \%$ & $95.33 \%$ \\
\hline \multirow[t]{3}{*}{ I calculated - I measured (ph A; ph B; ph C) } & $95.74 \%$ & $97.00 \%$ & $97.59 \%$ & $97.43 \%$ & $96.61 \%$ \\
\hline & $95.72 \%$ & $96.82 \%$ & $97.15 \%$ & $96.69 \%$ & $95.60 \%$ \\
\hline & $95.71 \%$ & $96.82 \%$ & $97.16 \%$ & $96.72 \%$ & $95.65 \%$ \\
\hline Bornholm & Os shift & 1s shift & 2s shift & 3s shift & 4s shift \\
\hline I calculated - I set & $97.34 \%$ & $83.12 \%$ & $72.24 \%$ & $75.40 \%$ & $83.21 \%$ \\
\hline \multirow[t]{3}{*}{ I set - I measured (ph A; ph B; ph C) } & $89.91 \%$ & $95.21 \%$ & $86.18 \%$ & $77.55 \%$ & $79.06 \%$ \\
\hline & $89.94 \%$ & $95.24 \%$ & $86.20 \%$ & $77.58 \%$ & $79.09 \%$ \\
\hline & $89.94 \%$ & $95.23 \%$ & $86.22 \%$ & $77.58 \%$ & $79.08 \%$ \\
\hline \multirow[t]{3}{*}{ I calculated - I measured (ph A; ph B; ph C) } & $85.55 \%$ & $95.19 \%$ & $89.36 \%$ & $78.59 \%$ & $77.03 \%$ \\
\hline & $85.61 \%$ & $95.22 \%$ & $89.38 \%$ & $78.62 \%$ & $77.05 \%$ \\
\hline & $85.59 \%$ & $95.21 \%$ & $89.37 \%$ & $78.59 \%$ & $77.02 \%$ \\
\hline
\end{tabular}

set current due to undershooting observed in Fig. 3 and Fig. 6. Notice that the results from Lyngby Campus is based on controlling the charging of $2 \mathrm{EVs}$ and is of higher correlation than Bornholm, although more delayed.

I calculated-I measured: This correlation is the most important metric, as it correlates the measured frequency and the measured power consumption. Both tests show similar results as the previous classes presented and is for Lyngby campus and Bornholm, $5 \mathrm{~s}$. and 1 s., respectively.

\section{CONCLUSION AND Future WORK}

The experimental results show that it is technically feasible to control the unidirectional charging of multiple commercial EVs simultaneously in order to PRF. The developed control architecture was successfully deployed and tested at multiple locations, where the performance of the controller was analytically evaluated by time shifting and correlating $I_{\text {set }}$ and $I_{\text {calculated }}$ and was found to be $98.66 \%$ and $97.34 \%$ for Lyngby Campus and Bornholm with a time shift of 0 s. The average time-shift was calculated for Lyngby campus and Bornholm and was $5 \mathrm{~s}$. and $1 \mathrm{~s}$., respectively. The results showed that the use of a third-party communication server have a negative impact of the response time of the system, as the average response time was decreased by $4 \mathrm{~s}$. by controlling the EVSE directly.

In order for a successful value-adding integration of EVs, a method for providing local down-regulation at feeder-level should be investigated. Such a system should be able to still provide frequency control but at aggregator level respect local network constraints and possible be able to provide local down-regulation.

\section{REFERENCES}

[1] M. Dugdale, "European countries banning fossil fuel cars and switching to electric." [Online]. Available: https://www.roadtraffictechnology.com/features/european-countries-banning-fossil-fuel-cars/

[2] IEA, “Global ev outlook 2018," IEA, Tech. Rep., 2018. [Online]. Available: https://www.iea.org/reports/global-ev-outlook-2018
[3] R. Bayindir, S. Demirbas, E. Irmak, U. Cetinkaya, A. Ova, and M. Yesil, "Effects of renewable energy sources on the power system," in 2016 IEEE International Power Electronics and Motion Control Conference (PEMC), 2016, pp. 388-393.

[4] N. DeForest, J. S. MacDonald, and D. R. Black, "Day ahead optimization of an electric vehicle fleet providing ancillary services in the los angeles air force base vehicle-to-grid demonstration," Applied Energy, vol. 210 , pp. $987-1001,2018$.

[5] S. Vandael, T. Holvoet, G. Deconinck, S. Kamboj, and W. Kempton, "A comparison of two giv mechanisms for providing ancillary services at the university of delaware," in 2013 IEEE International Conference on Smart Grid Communications (SmartGridComm), 2013, pp. 211-216.

[6] S. Kamboj, W. Kempton, and K. S. Decker, "Deploying power gridintegrated electric vehicles as a multi-agent system," 10th International Conference on Autonomous Agents and Multiagent Systems 2011, Aamas 2011, vol. 1, pp. 9-16, 2011.

[7] A. Thingvad, C. Ziras, and M. Marinelli, "Economic value of electric vehicle reserve provision in the nordic countries under driving requirements and charger losses," Journal of Energy Storage, vol. 21, pp. 826834, 2019.

[8] N. Banol Arias, S. Hashemi, P. Andersen, C. Traholt, and R. Romero, "V2g enabled evs providing frequency containment reserves: field results," in Proceedings of 2018 IEEE International Conference on Industrial Technology. United States: IEEE, 2018, pp. 1814-19.

[9] Energinet, "Ancillary services to be delivered in denmark tender conditions," Energinet, Tech. Rep., 2018. [Online]. Available: https://en.energinet.dk/-/media/Energinet/ElRGD/Dokumenter/Ancillary-services-to-be-delivered-in-Denmark.pdf

[10] International Electrotechnical Commission, "Electric vehicle conductive charging system - part 1: General requirements." [Online]. Available: https://webstore.iec.ch/publication/33644

[11] M. Marinelli, S. Martinenas, K. Knezovic, and P. Andersen, "Validating a centralized approach to primary frequency control with series-produced electric vehicles," Journal of Energy Storage, vol. 7, p. 63-73, 2016.

[12] K. Knezovic, S. Martinenas, P. Andersen, A. Zecchino, and M. Marinelli, "Enhancing the role of electric vehicles in the power grid: Field validation of multiple ancillary services," I E E E Transactions on Transportation Electrification, vol. 3, no. 1, pp. 201 - 209, 2016.

[13] R. J. Askjær, "Vertically integrated charging of electric vehicles," Master's thesis, Technical University of Denmark (DTU), 2016.

[14] A. Zecchino, A. Thingvad, P. Andersen, and M. Marinelli, "Test and modelling of commercial v2 $\mathrm{g}$ chademo chargers to assess the suitability for grid services," World Electric Vehicle Journal, vol. 10, no. 2, 2019. 